Bangladesh J.Pl. Breed. Genet., 23(1): 39-43, 2010

\title{
VARIABILITY AND CHARACTER ASSOCIATION OF REPRODUCTIVE TRAITS IN EXOTIC RICE GERMPLASM
}

\author{
T. Akter, N. A. Ivy, M. G. Rasul and M. A. K. Mian \\ Department of Genetics and Plant Breeding \\ Bangabandhu Sheikh Mujibur Rahman Agricultural University \\ Gazipur 1706, Bangladesh.
}

\begin{abstract}
Fifty two genotypes were evaluated to find out the genetic variability, character association, and path coefficient for reproductive traits of exotic rice germplasm in experimental field of Bangabandhu Sheikh Mujibur Rahman Agricultural University, Salna, Gazipur during December 2008 to May 2009. The analysis of variance showed significant variation for all the characters indicating wide genetic variability among the genotypes. The highest genotypic variance and phenotypic variance were found for pollen sterility and filled grains per panicle. High heritability and genetic advance were recorded for pollen sterility. Filled grains per panicle, days to $50 \%$ flowering, and pollen sterility of different genotypes had a high degree of significant positive association with grain yield per hill. On the basis of genetic parameters, associations and path analysis 52 genotypes might be selected considering the filled grains per panicle only.
\end{abstract}

Key words: Variability, correlation coefficient, path coefficient, exotic rice

\section{INTRODUCTION}

Rice is grown predominately in tropical and subtropical countries over a wide range of soil and climatic condition and one of the major and most extensively cultivated cereals of the world. It is predicted that the population in the world will increase continuously from the current 6 to 8 billion in 2030. Facing the challenge of population growth and cropland reduction, it is obvious that the only way to solve this problem is to improve the yield of cereal crops namely, rice, wheat and corn etc. (Yuan and Peng, 2005). Evaluation and characterization of potential varieties should form an important constituent of collection efforts because of their in-built genetic variability due to several generations of growing and selection by breeders and farmers. However, the utilization of these rice genetic resources had been limited to only adaptable genotypes (Caldo et al., 1996). As a result, the diversity of these genetic resources is being lost to the need for higher yields and early maturity. However, a successful breeding program will depend on the genetic diversity of a crop for achieving the goals of improving the crop and producing high yielding and better resistant varieties (Padulosi, 1993). Therefore, there is need to diversify the genetic base of rice varieties and the first step towards this is to evaluate variability of reproductive traits in exotic rice germplasm. There may be a chance of cultivation of exotic rice and can be used in further breeding program in this country, if high production is possible due to presence of a wide range of genetic variability in these exotic rice. The present investigation has been undertaken to study variability, correlation and path coefficient analysis in reproductive traits of exotic rice germplasm. 


\section{MATERIALS AND METHODS}

The experiment was carried out at the experimental field of Bangabandhu Sheikh Mujibur Rahman Agricultural University, Salna, Gazipur during December, 2008 to May, 2009 using 50 exotic rice genotypes and two variety. The experimental plots were laid out in randomized complete block design (RCBD) with three replications. The plot size was $12.5 \mathrm{~m} \times 2.5 \mathrm{~m}$. Forty days old seedlings were transplanted with a spacing of $25 \mathrm{~cm}$ and $20 \mathrm{~cm}$ between rows and between plants, respectively. The experimental plot was fertilized by applying urea, TSP, MP and Gypsum @ 180-100-70-60 Kg/ha, respectively. Total TSP, MP and Gypsum were applied at final land preparation. Total urea was applied in three installments, at 15 days after transplanting (DAT), 30 DAT and 50 DAT recommended by BSMRAU (Anon., 1999). Necessary intercultural operation was made during cropping period for proper growth and development of the plants. Irrigation with regular interval was given to maintain 5-7 $\mathrm{cm}$ water up to hard dough stage of rice.

Data were collected from 5 hills of each genotype on individual plant basis on days to first flowering (DFF), days to 50\% flowering (50\%DF), days to harvesting (DH), pollen sterility (PS), spikelet sterility (SS), filled grains per panicle (FGP), grain length $(\mathrm{GL})$, grain breadth $(\mathrm{GB})$ and grain yield per hill $(\mathrm{GYH})$. The statistical analysis for various characters under investigation were done and the analysis of variance for each of the characters was performed by F test and mean values were separated by LSD method. Variability, correlation coefficient and path coefficient analysis was performed (Burton, 1952, Johnson et al., 1955 and Singh and Chaudhary, 1985).

\section{RESULTS AND DISCUSSION}

\section{Variability in exotic rice genotypes}

The extent of variability for any character is very important for the improvement of a crop through breeding. The estimates of Mean sum of squares due to genotypes $\left(\mathrm{MS}_{\mathrm{G}}\right)$, range, genotypic variation $\left(\sigma^{2} \mathrm{~g}\right)$, phenotypic variation $\left(\sigma^{2} \mathrm{p}\right)$, genotypic coefficient of variation (GCV), phenotypic coefficient of variation (PCV), heritability $\left(h^{2}\right)$ and genetic advance (GA) for different characters have been presented in Table 1. The highest $\sigma^{2} \mathrm{~g}$ was found for pollen sterility (960.086) and the lowest magnitude of $\sigma^{2} \mathrm{~g}$ was observed in grain breadth (0.167). The highest $\sigma^{2} \mathrm{p}$ was found for filled grains per panicle (980.866) and the lowest magnitude of $\sigma^{2} \mathrm{p}$ was observed in grain breadth (mm) (0.181). The GCV and PCV were the highest for percent pollen sterility (48.940 and 49.027) followed by spikelet sterility (44.247 and 48.252) and grain yield per hill (g) (28.243 and 30.785) (Table 1). High GCV and PCV for pollen sterility, spikelet sterility and grain yield per hill $(\mathrm{g})$ indicated that selection of these traits would be effective. The GCV and PCV were the lowest for days of harvesting (3.246 and 3.333) and days of first flowering (6.637 and 6.735). PCV were slightly higher than GCV in case of all the traits, indicating presence of environmental influence to some degrees in the phenotypic expression of the characters. High GCV and PCV were recorded for pollen sterility, spikelet sterility and grain yield per hill $(\mathrm{g})$, but it was moderate for filled grains per panicle $(24.830$ and $26.395 \mathrm{~mm})$, grain breadth $(13.566$ and $14.116 \mathrm{~mm})$ and grain length (12.743 and $13.164 \mathrm{~mm})$. Days to harvesting and days to first flowering exhibited low genotypic as well as phenotypic coefficient of variations in the present study, which may be due to presence of both positive and negative alleles in the population. These results were in conformity with the findings of Pandey and Awasthi (2002) for significant genetic variability among the 21 genotypes for all the yield contributing traits. High 
heritability was observed in pollen sterility (99.648\%), days to $50 \%$ flowering (97.968), grain length $(93.710 \mathrm{~mm})$, grain breadth $(92.364 \mathrm{~mm})$ and in case of days of first flowering (97.113), days of harvesting (94.813) GCV was low with high $h^{2}$. High heritability estimates have been found to be effective in the selection of superior genotypes on the basis of phenotypic performance. High heritability associated with high genetic advance was obtained in pollen sterility. Grain yield per hill, filled grains per panicle and spikelet sterility had moderate heritability with moderate genetic advance. The high heritability estimates along with low genetic advance indicates that nonadditive type of gene action and genotype-environment interaction plays a significant role in the expression of the trait as observed in days to first flowering, days to $50 \%$ flowering, days to harvesting, grain length and grain breadth. Pollen sterility had high heritability with high genetic advance along with moderate heritability and moderate genetic advance in grain yield per hill, filled grains per panicle and spikelet sterility made these characters most effective in the selection of exotic rice. Chetia et al. (2000) has reported significant variability for pollen and spikelet sterility and Sadhukhan and Chattopadhyay (2000) has also reported moderate to high GCV and PCV values, Broad sense heritability and genetic gain as percentage of population mean for some yield contributing attributes and grain quality.

Table 1. Estimation of genetic parameters of 52 genotypes

\begin{tabular}{|c|c|c|c|c|c|c|c|c|c|}
\hline Characters & $\mathbf{M S}_{\mathbf{G}}$ & Range & Mean & $\sigma^{2} g$ & $\sigma^{2} \mathbf{p}$ & GCV & PCV & $\mathbf{h}^{2}{ }_{b}$ & GA \\
\hline DFF & 182.06 & $106.00-132.67$ & 116.80 & 60.09 & 61.87 & 6.63 & 6.73 & 97.11 & 13.47 \\
\hline $50 \% \mathrm{DF}$ & 218.59 & $112.00-139.67$ & 122.82 & 72.36 & 73.86 & 6.92 & 6.99 & 97.96 & 14.12 \\
\hline DH & 73.14 & $145.33-160.33$ & 150.76 & 23.94 & 25.25 & 3.24 & 3.33 & 94.81 & 6.51 \\
\hline PS & 2883.65 & $1.33-97.99$ & 63.31 & 960.08 & 963.47 & 48.94 & 49.02 & 99.64 & 100.63 \\
\hline SS & 300.42 & $5.43-51.60$ & 21.94 & 94.20 & 112.02 & 44.24 & 48.25 & 84.09 & 83.58 \\
\hline FGP & 2716.83 & $42.00-187.93$ & 118.65 & 867.98 & 980.86 & 24.83 & 26.39 & 88.49 & 48.11 \\
\hline GL & 4.05 & $6.19-13.07$ & 9.01 & 1.31 & 1.40 & 12.74 & 13.16 & 93.71 & 25.41 \\
\hline GB & 0.52 & $2.36-3.94$ & 3.01 & 0.16 & 0.18 & 13.56 & 14.11 & 92.36 & 26.85 \\
\hline GYH & 69.77 & $6.59-24.34$ & 16.56 & 21.88 & 26.00 & 28.24 & 30.78 & 84.16 & 53.37 \\
\hline
\end{tabular}

$\mathrm{MS}_{\mathrm{G}}=$ Mean sum of squares due to genotypes, $\sigma^{2} \mathrm{~g}=$ Genotypic variance, $\sigma^{2} \mathrm{p}=$ Phenotypic variance, $\mathrm{GCV}=$ Genotypic coefficient of variation, $\mathrm{PCV}=$ Phenotypic coefficient of variation, $\mathrm{h}_{\mathrm{b}}^{2}=$ Heritability and GA = Genetic advance. DFF = Days to first flowering, $50 \% \mathrm{DF}=$ Days to $50 \%$ flowering, DH = Days to harvesting, PS = Pollen sterility $\%$, SS $=$ Spikelet sterility $\%$, FGP $=$ Filled grains per panicle, $\mathrm{GL}=$ Grain length $(\mathrm{mm}), \mathrm{GB}=$ Grain breadth $(\mathrm{mm}), \mathrm{GYH}=$ Grain yield per hill (g).

\section{Character association}

Character association study among reproductive traits (Table 2) revealed that in most of the cases the genotypic correlation coefficients were higher than the corresponding phenotypic correlation coefficients. Grain yield showed positive and significant association with filled grain per panicle both in genotypic and phenotypic levels (Table 2). Days to first flowering showed significant and positive correlation with days to $50 \%$ flowering at both genotypic and phenotypic level. Days to harvesting showed significant positive correlation with days to first flowering and days to $50 \%$ flowering at both genotypic and phenotypic level. Grain length showed significant and positive correlation with spikelet sterility and significant negative correlation with filled grains per panicle at both genotypic and phenotypic level. 
Filled grains per panicle and grain yield had highly significant and negative association with spikelet sterility (\%) at both genotypic and phenotypic level as well as grain breadth showed negative association with grain length at both genotypic and phenotypic level. Filled grains per panicle also showed negative association with spikelet sterility (\%). Similar associations in rice were also reported by Ogunbayo et al. (2005).

Table 2: Genotypic $\left(r_{g}\right)$ and phenotypic $\left(r_{p}\right)$ Correlation coefficient among 52 rice genotypes

\begin{tabular}{|c|c|c|c|c|c|c|c|c|c|}
\hline Parameters & & $50 \%$ DF & DH & PS & SS & FGP & GL & GB & GYH \\
\hline \multirow[t]{2}{*}{ DFF } & $\mathrm{r}_{\mathrm{g}}$ & $0.984 * *$ & $0.858^{* *}$ & 0.149 & 0.235 & -0.032 & 0.259 & -0.037 & 0.0993 \\
\hline & $r_{p}$ & $0.975^{* *}$ & $0.826^{* *}$ & 0.147 & 0.214 & -0.035 & 0.239 & -0.030 & 0.088 \\
\hline \multirow[t]{2}{*}{$50 \%$ D F } & $r_{g}$ & & $0.848^{* *}$ & 0.213 & 0.236 & -0.030 & 0.251 & 0.009 & 0.111 \\
\hline & $\mathrm{r}_{\mathrm{p}}$ & & $0.817^{* *}$ & 0.212 & 0.223 & -0.035 & 0.238 & 0.008 & 0.098 \\
\hline \multirow[t]{2}{*}{ DH } & $r_{g}$ & & & 0.050 & 0.262 & -0.138 & 0.253 & 0.012 & 0.001 \\
\hline & $r_{p}$ & & & 0.048 & 0.246 & -0.134 & 0.241 & 0.010 & -0.002 \\
\hline \multirow[t]{2}{*}{ PS } & $r_{g}$ & & & & 0.133 & 0.113 & -0.016 & -0.015 & 0.189 \\
\hline & $r_{p}$ & & & & 0.124 & 0.106 & -0.018 & -0.012 & 0.172 \\
\hline \multirow[t]{2}{*}{ SS } & $\mathrm{rg}_{\mathrm{g}}$ & & & & & $-0.405 * *$ & $0.361 * *$ & 0.096 & $-0.429 * *$ \\
\hline & $r_{p}$ & & & & & $-0.409 * *$ & $0.320^{*}$ & 0.077 & $-0.368^{* * *}$ \\
\hline \multirow[t]{2}{*}{ FGP } & $r_{g}$ & & & & & & $-0.369 * *$ & -0.069 & $0.596^{* *}$ \\
\hline & $r_{p}$ & & & & & & $-0.332 *$ & -0.082 & $0.581^{* *}$ \\
\hline \multirow[t]{2}{*}{ GL } & $r_{g}$ & & & & & & & $-0.390 * *$ & -0.075 \\
\hline & $r_{p}$ & & & & & & & $-0.391 * *$ & -0.075 \\
\hline \multirow[t]{2}{*}{ GB } & $r_{g}$ & & & & & & & & -0.138 \\
\hline & $r_{p}$ & & & & & & & & -0.115 \\
\hline
\end{tabular}

$* \& * *$ indicates significant at $5 \%$ and $1 \%$ level of significance

$\mathrm{r}_{\mathrm{g}}=$ genotypic correlation coefficient and $\mathrm{r}_{\mathrm{p}}=$ phenotypic correlation coefficient

$\mathrm{DFF}=$ Days to first flowering, $50 \% \mathrm{DF}=$ Days to $50 \%$ flowering, $\mathrm{DH}=$ Days to harvesting, $\mathrm{PS}=$ Pollen sterility $\%, \mathrm{SS}=$ Spikelet sterility $\%, \mathrm{FGP}=$ Filled grains per panicle, GL = Grain length $(\mathrm{mm}), \mathrm{GB}=$ Grain breadth $(\mathrm{mm}), \mathrm{GYH}=$ Grain yield per hill $(\mathrm{g})$.

However, the correlation study revealed that grain yield, days to first flowering, days to $50 \%$ flowering, days to harvesting, spikelet sterility (\%), filled grain per panicle, grain length and grain breadth were the important characters to be considered in the selection for improvement of exotic rice genotypes.

\section{Path coefficient analysis}

Partitioning of genotypic correlation of reproductive traits in exotic genotypes is presented in Table 3. Path coefficient analysis (Table 3 and Fig. 1) showed that filled grains per panicle had maximum direct effect $(0.321)$ on yield followed by grain length (0.266), pollen sterility (0.143), days to 50\% flowering (0.125) and grain breadth (0.057). The lowest direct effect on grain yield was exhibited by days to first flowering and spikelet sterility (0.023). The highest positive indirect effects on grain yield were obtained by days to harvesting $(0.106)$ followed by grain length $(0.059)$, spikelet sterility $(0.030)$ and negative indirect effects on filled grains per panicle $(-0.009)$. Highly significant positive correlation with positive direct effect was observed in filled grains per panicle. So, filled grains per panicle was the only selection trait for these exotic rice genotypes. Among the yield and yield related traits, filled grains per panicle had high direct positive effect on grain yield as reported earlier by Samonte et al. (1998) and Mahto et al. (2003). The residual effect of the present study was 0.713 indicating $29 \%$ of 
the variability of grain yield per hill was contributed by the nine characters studied in the path analysis.

Table 3. Partitioning of genotypic correlation with grain yield into direct (bold) and indirect effect in 52 genotypes

\begin{tabular}{llllllllll}
\hline Parameters & DFF & $\begin{array}{l}\mathbf{5 0} \% \\
\text { DF }\end{array}$ & DH & PS (\%) & SS (\%) & FGP & GL & GB & $\begin{array}{l}\text { Correlation } \\
\text { with GYH (g) }\end{array}$ \\
\hline DFF & $\mathbf{0 . 0 2 3}$ & 0.123 & 0.024 & 0.021 & 0.005 & -0.010 & 0.069 & -0.002 & 0.0993 \\
50\%DF & 0.022 & $\mathbf{0 . 1 2 5}$ & 0.024 & 0.030 & 0.005 & -0.010 & 0.067 & 0.000 & 0.111 \\
DH & 0.019 & 0.106 & $\mathbf{0 . 0 2 8}$ & 0.007 & 0.006 & -0.044 & 0.067 & 0.001 & 0.001 \\
PS (\%) & 0.003 & 0.027 & 0.001 & $\mathbf{0 . 1 4 3}$ & 0.003 & 0.036 & -0.004 & -0.001 & 0.189 \\
SS (\%) & 0.005 & 0.030 & 0.007 & 0.019 & $\mathbf{0 . 0 2 3}$ & -0.130 & 0.096 & 0.005 & $-0.429 * *$ \\
FGP & -0.001 & -0.004 & -0.004 & 0.016 & -0.009 & $\mathbf{0 . 3 2 1}$ & -0.098 & -0.004 & $0.596^{* *}$ \\
GL & 0.006 & 0.031 & 0.007 & -0.002 & 0.008 & -0.118 & $\mathbf{0 . 2 6 6}$ & -0.022 & -0.075 \\
GB & -0.001 & 0.001 & 0.000 & -0.002 & 0.002 & -0.022 & -0.103 & $\mathbf{0 . 0 5 7}$ & -0.138 \\
\hline R (Res
\end{tabular}

$\mathrm{R}($ Residual Effect $)=0.713$

$\mathrm{DFF}=$ Days to first flowering, $50 \% \mathrm{DF}=$ Days to $50 \%$ flowering, $\mathrm{DH}=$ Days to harvesting, $\mathrm{PS}=$ Pollen sterility $\%$, SS $=$ Spikelet sterility $\%, \mathrm{FGP}=$ Filled grains per panicle, GL $=$ Grain length $(\mathrm{mm}), \mathrm{GB}=$ Grain breadth $(\mathrm{mm}), \mathrm{GYH}=$ Grain yield per hill $(\mathrm{g})$.

Based on genetic parameters, character association and path analysis filled grains per panicle was the only selection trait for the improvement of 50 exotic genotypes of rice.

\section{REFERENCES}

Anonymous. 1999. Time and requirement of topdressing of urea according to season and variety. Adhunik Dhaner Chash, Bangladesh Rice Res. Inst., 28p.

Caldo, R. A, L. S. Sebastian, J. E. Hernandez. 1996. Morphology-Based Genetic Diversity Analysis of Ancestral Lines of Rice in Philippine Rice Cultivars. Philippines Journal of Crop Sci. 21(3): 86-92.

Chetia, S., R. P. Borkakati and R. K. Chowdhury. 2000. Studies on stability of vegetative and floral traits of cytoplasmic male sterile lines in rice. J. Agril. Sci. Soc. North East India. 13(2): 222-224.

Mahto, R. N., M. S. Yadava and K. S. Mohan. 2003. Genetic variation, character association and path analysis in rainfed upland rice. Indian Journal of Dryland Agricultural Research and Development. Central Research Institute for Dryland Agriculture. Hyderabad, India. 18(2): 196-198.

Ogunbayo, S., D. K. Ojo, R. G. Guei, O. O. Oyelakin and K. A. Sanni. 2005. Phylogenetic diversity and relationships among 40 rice accessions using morphological and RAPDs techniques. African J. Biotech. 4 (11): 1234-1244.

Padulosi, S. 1993. Genetic diversity, taxonomy and ecogeographical survey of the wild relatives of cowpea (Vigna unguiculata (L.) Walp). Ph. D Thesis. p. 346.

Pandey, V. K. and L. P. Awasthi. 2002. Studies on genetic variability for yield contributing traits in aromatic rice. Crop Res. Hisar. 23(2): 214-218.

Sadhukhan, R. N. and P. Chattopadhyay. 2000. Variability and character association between yield attributes and grain quality in aromatic rice. J. Interacademicia. 4(4): 494-497. 
Samonte, S. O. P. B., L. T. Wilson and A. M. McClung. 1998. Path analyses of yield and yield related traits of fifteen diverse rice genotypes. Crop Sci. 38(5): 1130-1136.

Yuan, L. P. and J. M. Peng. 2005. Hybrid Rice and World Food Security. China Science and Technology Press, Beijing.

Burton, G. W. 1952. Quantitative inheritance in grasses. Proc. $6^{\text {th }}$ Int. Grassland, Cong; 1: $277-283$

Johnson, H.W., H.F. Robinson and R. E. Comstock. 1955. Estimates of genetic and environmental variability in soyabean. Agron. J. 47: 314-318

Singh, R. K. and B. D. Choudhury. 1985. Biometrical Methods in Quantitative Genetic Analysis. Rev Edn., Kalyani Publisher. 318p. 